13. Fizychna kultura: Prohrama dlia zahalnoosvitnikh navchalnykh zakladiv: 1-4 klasy. Zdorovia ta fizychna kultura. Shkilnyi svit. 2013; 6: 1-24.

14. Chalii LV. Formuvannia hotovnosti maibutnikh uchyteliv fizychnoi kultury do orhanizatsii pozaklasnoi roboty z turyzmu [avtoreferat]. Rivne: Rivnenskyi derzh. humanitarn.un-t; 2017. 22 s.

Цитування на цю статтю:

Ткачівська IM, Іванишин IM, Презлята ГВ, Дмитришин Д. Стан фізичної підготовленості дітей 10-ти років як критерій готовності до занять активним туризмом. Вісник Прикарпатського університету. Серія: Фізична культура. 2019 Берез 26; 33: 142-153

\begin{tabular}{|c|c|}
\hline Iá. & ormation about the author: \\
\hline $\begin{array}{l}\text { Ткачівська Інна Михайлівна - кандидат педаго- } \\
\text { гічних наук, доцент, ДВНЗ “Прикарпатський на- } \\
\text { ціональний університет імені Василя Стефаника" } \\
\text { (Івано-Франківськ, Україна) }\end{array}$ & $\begin{array}{l}\text { Tkachivska Inna Mykhailivna - Candidate of Science } \\
\text { (Education), Associate Professor (Ph. D.), Vasyl } \\
\text { Stefanyk Precarpathian National University (Ivano- } \\
\text { Frankivsk, Ukraine) }\end{array}$ \\
\hline \multicolumn{2}{|l|}{$\begin{array}{l}\text { e-mail: Inna.tkachivska @ gmail.com } \\
\text { https://orcid.org/0000-0002-8995-2483 }\end{array}$} \\
\hline $\begin{array}{l}\text { Іванишин Ірина Мирославівна-1 } \\
\text { них наук, доцент, ДВНЗ “Прикарг } \\
\text { нальний університет імені Васи. } \\
\text { (Івано-Франківськ, Україна) }\end{array}$ & $\begin{array}{l}\text { Ivanyshyn Iryna Myroslavivna - Candidate of } \\
\text { Science (Chemistry), Associate Professor (Ph. D.), } \\
\text { Vasyl Stefanyk Precarpathian National University } \\
\text { (Ivano-Frankivsk, Ukraine) }\end{array}$ \\
\hline \multicolumn{2}{|l|}{$\begin{array}{l}\text { e-mail: Iraivan68@gmail.com } \\
\text { https://orcid.org/0000-0003-1765-8311 }\end{array}$} \\
\hline $\begin{array}{l}\text { Презлята Ганна Василівна - кандида } \\
\text { гічних наук, доцент, ДВНЗ “Прикарпатс } \\
\text { ціональний університет імені Василя Ст } \\
\text { (Івано-Франківськ, Україна) }\end{array}$ & $\begin{array}{l}\text { Prezliata Hanna Vasylivna - Candidate of Science } \\
\text { (Education), Associate Professor (Ph. D.), Vasyl } \\
\text { Stefanyk Precarpathian National University (Ivano- } \\
\text { Frankivsk, Ukraine) }\end{array}$ \\
\hline \multicolumn{2}{|l|}{ https://orcid.org/0000-0001-9981-82 } \\
\hline $\begin{array}{l}\text { Дмитришинн Дмитро Михай. } \\
\text { Івано-Франківський національю } \\
\text { верситет (Івано-Франківськ, Уке }\end{array}$ & $\begin{array}{l}\text { Dmytryshyn Dmytro Mykhailovych-lecturer, I } \\
\text { Frankivsk National Medical University (I } \\
\text { Frankivsk, Ukraine) }\end{array}$ \\
\hline
\end{tabular}

УДК 796.015.134:159.9.075.5

doi: 10.15330/fcult.33.153-160

Ніна Долбишева, Анна Михайліченко

\title{
ВЗАСМОЗВ'ЯЗОК ПОКАЗНИКІВ ТЕХНІЧНОЇ ПІДГОТОВЛЕНОСТІ СПОРТСМЕНІВ-ЧЕРЛІДИРІВ НА ЕТАПІ ПОПЕРЕДНЬОЇ БАЗОВОЇ ПІДГОТОВКИ
}

В даній статті проаналізовані та виявлені слабкі, середні $і$ сильні взаємозв'язки показників технічної підготовленості черлідирів на етапі попередньої базової підготовки. Так як, спортсменичерлідири виконують різні функиії на гімнастичному килимі, одні спортсмени виконують базу, а інші флаєри (черлідири, які виконують безпосередньо піраміди) рівень технічної підготовленості черлідирів визначався окремо, в залежності від їх функцій. Тому $і$ корелячійний аналіз показників рівня технічної підготовленості був проведений окремо для черлідирів-бази і черлідирів-флаєрів.

Метою дослідження є виявлення найбільш сильних взаємозв'язків показників технічної підготовленості черлідирів.

Матеріал і методи. Теоретичний аналіз, педагогічне спостереження, методи математичної статистики.

У дослідженні брало участь 100 спортсменів-черлідирів, з них 50 черлідирів-флаєрів $i 50$ черлідирів-бази.

Ключові слова: черлідинг, черлідири-база, черлідери-флаєри, кореляційний аналіз, кореляційна матриця, коефіцієнти кореляиії, взаємозв'язок, технічна підготовленість. 
This article analyzes and identifies weak, medium, and strong relationships between indicators of technical readiness of cheerleaders at the stage of preliminary basic training. Since cheerleader athletes perform various functions on the gymnastic mat, some athletes perform the base, and others flyers (cheerleaders that perform the pyramids directly), the level of technical readiness of the cheerleaders was determined separately, depending on their functions. Therefore, a correlation analysis of indicators of the level of technical readiness was conducted separately for the cheerleader base and cheerleader flyers.

The aim of the study is to identify the strongest interrelations of indicators of technical readiness of cheerleaders. Material and methods. Theoretical analysis, pedagogical observation, methods of mathematical statistics. The study involved 100 athletes cheerleading, of which 50 cheerleader flyers and 50 cheerleading base. The correlation analysis made it possible to establish a relationship between the indicators of technical preparedness at the level of control tests by blocks. It has been established that in most strong and average interactions between the indices of control tests at the intra-group level that are reliable at $p \leq 0.05-0.001$. The obtained results confirm the scientific theoretical positions of V.N. Platonov, L.P.Matveev and practical researches of NG Dolbysheva, V.V.Kidonin and others. on the interdependence of individual indicators of technical fitness of athletes. The results of the correlation analysis led to the development of a technique for improving the level of technical preparedness of athletes-cheesecliders at the stage of preliminary basic training.

Key words: cheerleading, cheerleader-base, cheerleaders-flyers, correlation analysis, correlation matrix, correlation coefficients, interconnection, technical readiness.

Постановка проблеми й аналіз результатів останніх досліджень. Низка науковців зазначає, що у складно-координаційних видах спорту спортивний результат залежить від технічної майстерності виконання змагальних вправ $[2,5,9,14,16]$. Черлідинг э молодим видом спорту, який набув свого розвитку в Україні на початку XXI століття і також належить до складно-координаційних видів спорту, рухова діяльність яких характерна надзвичайно високими вимогами до техніки рухів і різних якостей $[1,2,13,16]$. Тому черлідинг вимагає граничної концентрації сил і часу під час тренування, прямо або опосередковано процесу підготовки до виступу в конкретних номерах змагальної програми. Ними було доведено, що пріоритетною стороною черлідирів є технічна підготовка, оскільки основним критерієм оцінки виступу команди на змаганнях є якість та складність виконання технічних елементів $[7,11,12]$.

Під технічною підготовленістю спортсмена розуміють ступінь засвоєння спортсменом системи рухів, відповідних особливостям даного виду спорту і спрямованої на досягнення високих спортивних результатів [5, 14].

Науковий пошук дозволив встановити, по-перше, що існують окремі наукові дослідження щодо визначення кореляційних зв'язків між показниками загальної та спеціальної фізичної підготовленості черлідирів [8] та інші дослідження в цьому напрямку $[4,6]$. По-друге при кореляційному аналізі показників технічної, тактичної, загальної і спеціальної фізичної підготовленості спортсменів можна визначити їх взаємозв'язки, які дозволять визначити пріоритети в плануванні тренувальних навантажень щодо підвищення чи вдосконалення рівня підготовленості в комплексі.

Такий стан питання робить актуальним проведення кореляційного аналізу рівня технічної підготовленості юних черлідирів на етапі попередньої-базової підготовки.

Мета дослідження - визначення кореляційних зв'язків між показниками технічної підготовленості на загальногруповому рівні та їх достовірність, результати яких будуть основою при розробці методики вдосконалення технічної підготовки спортсменок-черлідирів на етапі попередньої базової підготовки.

Методи та організація дослідження. Основними методами дослідження були: метод аналізу науково-методичної літератури, педагогічне тестування та методи математичної статистики (кореляційний аналіз та іiї достовірність за t-Стьюдента).

У дослідженні прийняли участь 100 спортсмени-черлідирів 9-11 років Дніпропетровської, Одеської та Київської областей, з яких 50 черлідирів, які виконують базу та 50 черлідирів-флаєрів. 
Результати і дискусія. Кореляційний аналіз здійснювався з метою визначення взаємозв'язків між показниками технічної та фізичної підготовленості, який дозволив виділити найбільші їх закономірності.

Ураховуючи те, що спортсмени-черлідири виконують різні функції на гімнастичному килимі, одні спортсмени виконують базу, а інші - флаєри (черлідири, які виконують безпосередньо піраміди) рівень технічної та фізичної підготовленості черлідирів визначався окремо [3, 9].

Оцінка технічної підготовленості черлідирів-бази здійснювалась за трьома блоками контрольних тестів: базові рухи (положення рук та рухова пам'ять), чер-стрибки (“Той-Тач”, "Пайп”, “Навколо світу”) та акробатичні елементи (переворот вперед на дві та одну ногу, переворот назад на одну ногу, темповий переворот вперед на дві ноги). Рівень технічної підготовленості черлідирів-флаєрів за чотирьома блоками, до них відносились вищезазначені три блоки та один блок контрольних тестів положення флаєра (“Скрапіон”, “Основна стійка", “Ліберті”, “Стег” “Прапорець”). Попередній аналіз результатів технічної підготовленості дівчат 9-12 років на етапі попередньої базової підготовки відповідає середньому рівню [7].

Кореляційний аналіз технічної підготовки черлідирів-бази дозволив встановити, що з 105 перемінних у 53 є взаємозв'язок, що складає 52,3\%. Високі коефіцієнти кореляції визначились у 17 показників (32,1\%), середні - у 27 (50,9\%), слабкі - у 9 $(17,0 \%)$. Зазначаємо, що 47 показників мають достовірність за t-Стьюдента при $\mathrm{p} \leq 0,001$ ( $\mathrm{r}=0,463-0,918), 3$ - при $\mathrm{p} \leq 0,01$ ( $\mathrm{r}=0,446-0,459)$ і лише 4 показниках при достовірність відсутня (табл. 1).

Розглядаючи результати кожного блоку контрольних тестів 3 технічної підготовки окремо, можна зазначити, що вони між собою мають середні та сильні кореляційні зв'язки $\mathrm{r}=0,463-0,918$, Так, блок контрольних тестів базових рухів між собою має сильний зв'язок $\mathrm{r}=0,849$, блок контрольних тестів чер-стрибків - три середні взаємозв'язки ( $\mathrm{r}=0,518-0,698)$, блок контрольних тестів акробатичних елементів - 45 зав'язків, 3 яких 15 сильних (r=0,731-0,918) та 30 середніх (r=0,446-0,696). Відзначимо, що найвищий коефіцієнт варіації визначився між контрольним тестами переворот вперед та назад на одну ногу, який склав $\mathrm{r}=0,918$.

Не визначилась достовірність кореляційної залежності між блоками контрольних тестів. Однак в окремих випадках існує слабка кореляційна залежність - між “руховою пам'яттю" з "Пайп" та "Навколо світу" ( $\mathrm{r}=0,249$ та $\mathrm{r}=0,240)$, між чер-стрибком "Пайп" та акробатичним елементом "Переворот боком" (r=0,204) і між чер-стрибком “Той-Тач" та акробатичним елементом "Рандат" ( $\mathrm{r}=0,226)$.

Результати кореляційного аналізу показників технічної підготовленості черлідирів-флаєрів практично ідентичні з результатами черлідирів-бази. Однак, незалежно від того, що серед 190 перемінних у 127 визначились взаємозв'язки різного рівня, що склало 66,8\%, з них високі коефіцієнти кореляції мають 18 показників (14,2\%), середні - 62 (48,8\%), слабкі - 47 (37,0\%). Констатуємо, що 84 показники кореляційної матриці мають достовірність за $\mathrm{t}-$ Стьюдента при $\mathrm{p} \leq 0,001$ ( $\mathrm{r}=0,491-0,809), 17-$ при $\mathrm{p} \leq 0,01$ $(\mathrm{r}=0,382-0,456), 8$ - при $\mathrm{p} \leq 0,05(0,297-0,336)$, а у 18 слабких кореляційних зв'язків достовірність відсутня ( $\mathrm{r}=0,201-0,278)$.

Аналіз результатів відповідно до кожного блоку контрольних тестів свідчить, що, як і черлідирів-бази, існує сильний зв'язок між контрольними тестами блоку базові рухи (r=0,0,809), 1 сильний та 2 середніх між контрольними тестами блоку чер-стрибки ( $\mathrm{r}=0,797$ та r=0,63-0,667 відповідно).

Зазначимо, що блок положення флаєра включав 5 контрольних тестів та мав 9 взаємозв'язків 310 можливих, з яких 1 сильний (r=0,738, між “Стег” та “Прапорець”), 
5 середніх ( $\mathrm{r}=0,429-0,668)$ та 3 слабких ( $\mathrm{r}=0,311-0,397)$. Визначилась відсутність зв’язку між “Скарпіон” i “Стейч”.

Блок контрольних тестів акробатичних елементів мають 45 зв'язків 345 можливих, з яких $44 \epsilon$ достовірними ( $\mathrm{p} \leq 0,05-0,001)$. Відзначимо, що коефіцієнти кореляції нижчі ніж у черлідирів-бази. Так, визначилось 9 сильних кореляційних зв'язків (r=0,714-0,781), 22 - середній ( $\mathrm{r}=0,508-0,691), 14$ - слабких (r=0,275-0,497). Достовірність кореляції не визначилась між показниками контрольним тестом "Переворот боком" та "Переворот назад на одну ногу.

Цікавим $є$ то, що контрольні тести блоків базові рухи та чер-стрибки мали значно більше слабких кореляційних зв'язків у 10 випадках з 50 можливих $(\mathrm{r}=0,202-0,263) 3$ контрольними тестами акробатичні елементи, у порівнянні з черлідирами-бази, які також не мають достовірності. Відзначаємо, що у 50 випадках з 50, визначився зв'язок між контрольними тестами положення флаєра та акробатичні вправи, з яких 6 - сильних ( $\mathrm{r}=0,704-0773), 34$ - середніх $(\mathrm{r}=0,503-0,668)$ та 10 - слабких $(\mathrm{r}=0,254-0,456)$, один 3 який не має достовірності між тестом “Основна стійка" та "Переворот боком".

Порівняльний аналіз показників взаємозв'язків з технічної підготовленості між черлідирами-бази та черлідирами-флаєрами свідчить, що:

- загальна кількість кореляційних зв'язків у відсотковому відношенні черлідерівфлаєрів більша ніж у черлідирів-бази и складає 66,8\% та 52,3\% відповідно;

- співвідношення сильних та слабких кореляційних зв'язків має суттєві відмінності у порівнянні з середніми у кореляційниз зв'язках черлідирів-бази та черлідирів-флаєрів (рис. 1);

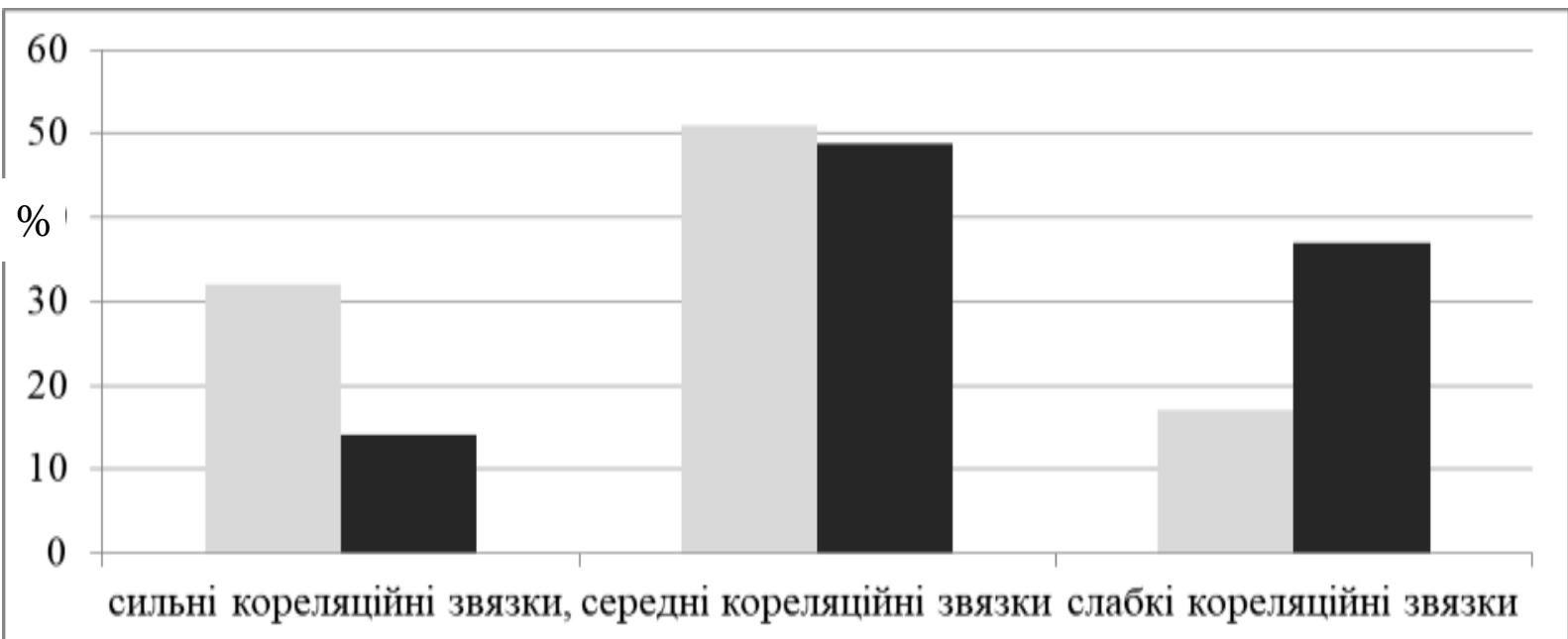

Рuc. 1. Співвідношення кореляційних зв'язків показників технічної підготовленості спортсменів-черлідирів: $\square$ - черлідири-бази, $\square$ - черлідири-флаєри

- достовірні коефіцієнтів кореляції показників технічної підготовленості в більшості прослідковуються у черлідирів-бази оскільки з 53 можливих 49 показників мають достовірність, що складає 92,5\%, при цьому у черлідерів-флаєрів 3127 можливих достовірність мають 109 коефіцієнтів, що складає 85,8\%.

Таким чином, проведений кореляційний аналіз свідчить взаємозалежність показників технічної підготовленості між собою. 
Долбишева Ніна, Михайліченко Анна. Взаємозв'язок показників технічної підготовленості спортсменів ...

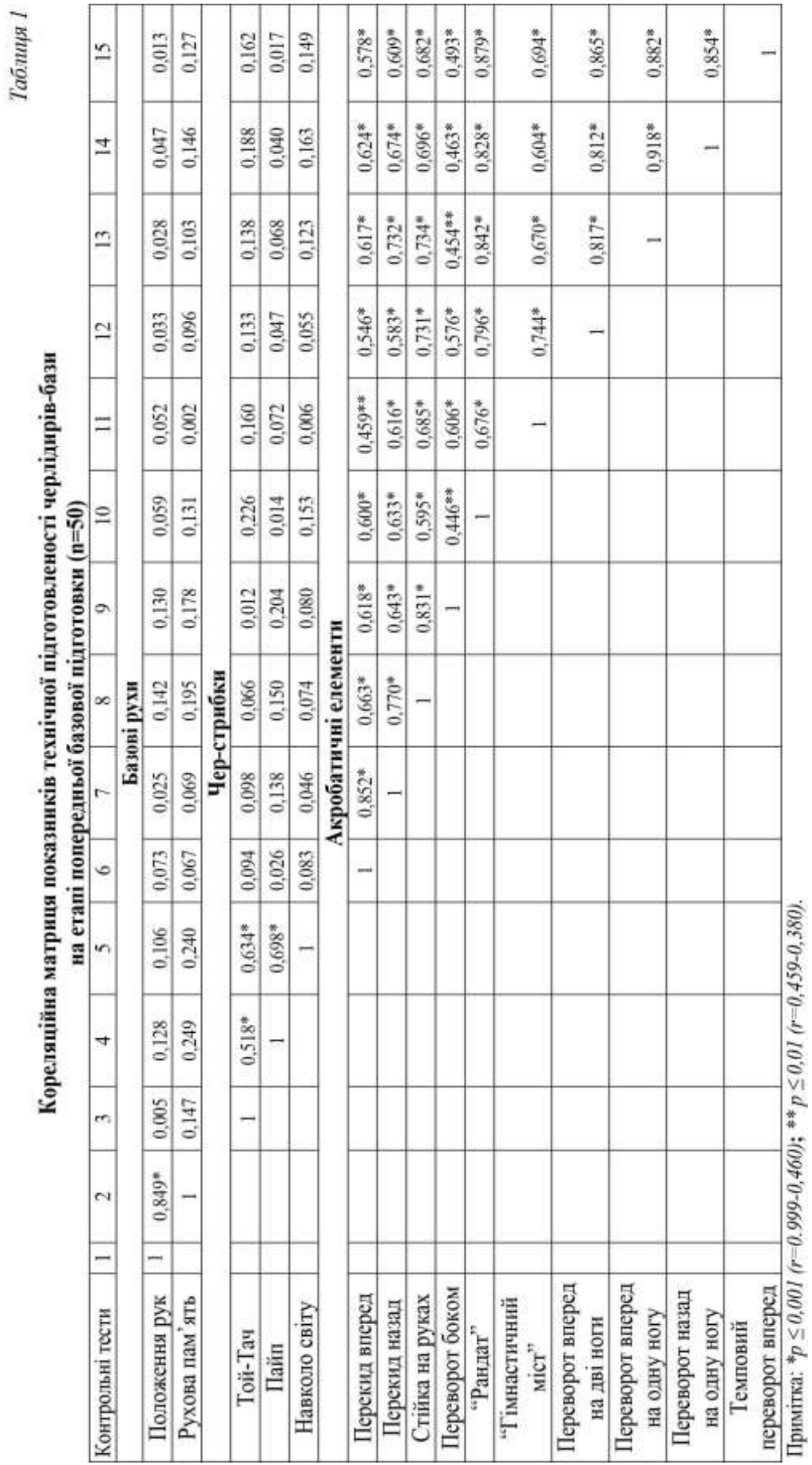




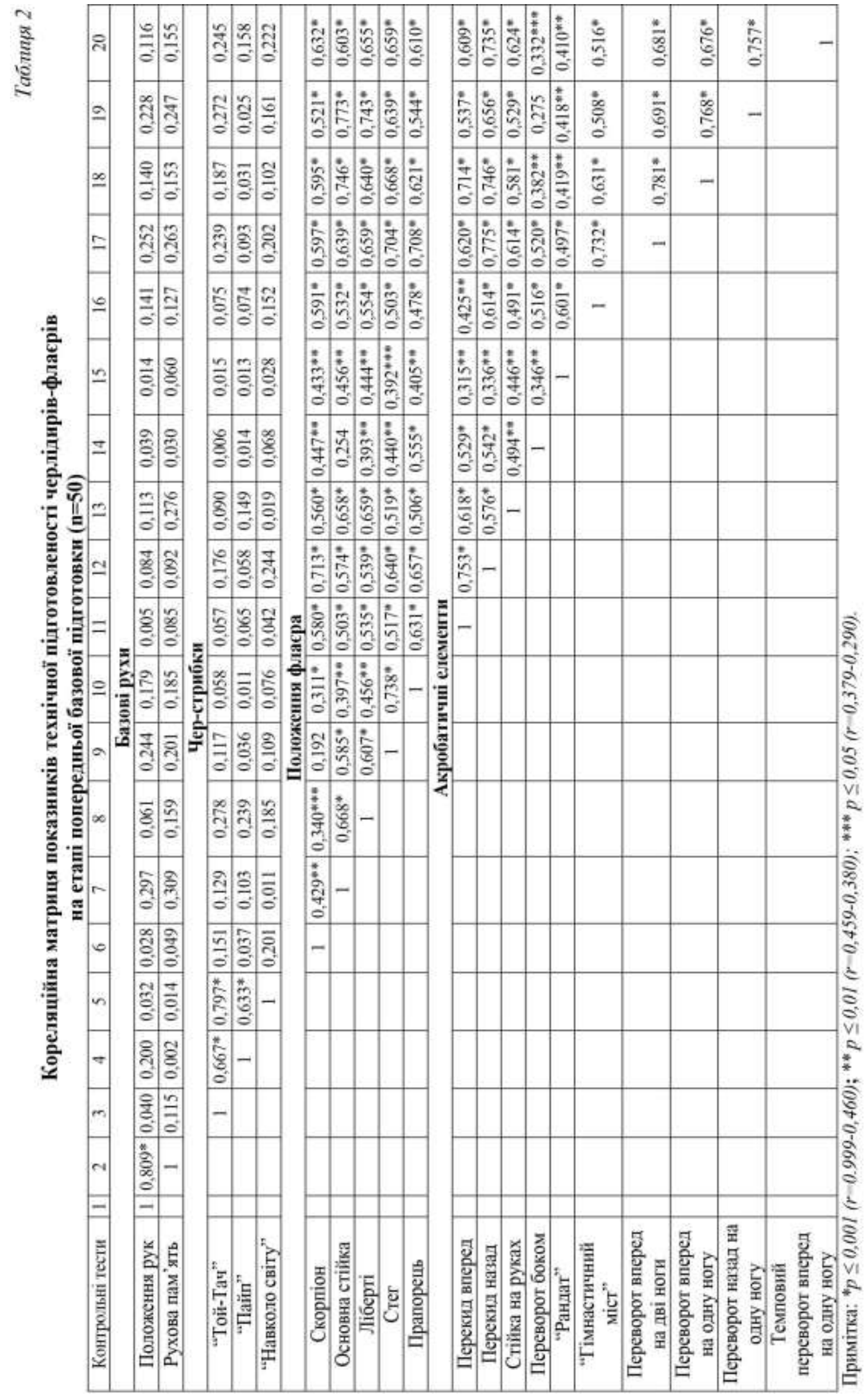


Висновки. Проведений кореляційний аналіз дозволив становити взаємозв'язки між показниками технічної підготовленості на рівні контрольних тестів за блоками. Встановлено, що прослідковуються в більшості сильні та середні взаємозв'язки між показниками контрольних тестів на внутрішньогруповому рівні, які мають достовірність при $\mathrm{p} \leq 0,05-0,001$.

Отримані результати підтверджують наукові теоретичні положення В. Н. Платонова, Л. П. Матвеєва та практичні дослідження Н. Г. Долбишевої, В. В. Кидонь та ін. щодо взаємозалежностей окремих показників технічної підготовленості спортсменів.

Результати кореляційного аналізу лягли в основу розробки методики вдосконалення рівня технічної підготовленості спортсменів-черлідирів на етапі попередньої базової підготовки.

Перспектива подалыших досліджень полягає у проведені кореляційного показників фізичної підготовленості та у визначенні їх взаємозв'язку з показниками технічної підготовленості відповідно до виконуючих функцій чарлідирів.

1. Афтайкин ВС. Применение усложнённых упражнений для развития координационных способностей юных черлидиров на начальном этапе обучения. Ученые записи университета имени П.Ф. Лесгафта, 2015; 5: 24.

2. Бекетова АН. “Черлидинг”: Методические указания. Харьков, 2017. 19 с.

3. Боляк АА. Чирлідинг : Правила змагань. Харків, 2005. 82 с.

4. Волков ЛВ. Теория и методика детского и юношеского спорта: Учебник. Київ: Олимпийская литература, 2002. 245 c.

5. Гавердовский ЮК. Теория и методика спортивной гимнастики : Учебник в 2-х т. М. : Советский спорт, 2014.

6. Долбишева НГ, Кидонь В. Закономірності взаємозв'язку технічної, фізичної підготовленості та функціонального стану спортсменок, які займаються естетичною гімнастикою. Фізична культура, спорт та здоров’я нації: збір. наук. праць. Житомир : Видавець О.О. Свенок, 2017; 4 (23): 30-36.

7. Долбишева НГ, Михайліченко АГ. Технічна та фізична підготовленість черлідирів-флаерів на етапі попередньої базової підготовки. Спортивний вісник Придніпров'я. Дніпро, 2018; 2: 22-26.

8. Луценко ЛС, Бодренкова ИА. Взаимосвязь показателей общей и специальной физической подготовленности спортсменов-черлидеров на этапе специализированной базовой подготовки. Физическое воспитание студентов. 2013; 6: 43-49. doi:10.6084/m9.figshare.840502

9. Матвеев ЛП. Общая теория спорта и ее прикладные аспекты : учеб. пособие для вузов физической культуры. 5-е изд., испр. и доп. Москва : Советский спорт, 2010. 340 с.

10. Зинченко ИА, Луценко ЛС, Боляк АА. Управление тренировочным процессом на основе моделирования показателей физической подготовленности спортсменов-черлидеров специализированного этапа подготовки. Слобожанський науково-спортивний вісник. Харків, 2010; 2: 52.

11. Михайліенко АГ. Технічна підготовка в навчально-тренувальному процесі юних спортсменів-черлідирів на етапі попередньої базової підготовки. Спортивний вісник Придніпров'я. Дніпро, 2018; 1: 55-58.

12. Михайліченко АГ. Методика вдосконалення технічної підготовки черлідирів на етапі попередньої базової підготовки. Науковий часопис національного педагогічного університету ім. М.П. Драгоманова. Науково-педагогічні проблеми фізичної культури. Фізична культура і спорт: зб. наук. праць / За ред. Г.А. Аорзютова. Київ: Вид-во НПУ ім. М.П. Драгоманова, 2018.

13. Носкова СА. Черлидинг как инновационный вид спорта в преподавании физической культуры в высшей школе. Теория и практика физической культуры. Харьков, 2002; 6: 49-51.

14. Платонов ВН. Система подготовки спортсменов в олимпийском спорте. Общая теория и ее практические приложения. Киев : Олимпийская литература, 2015. 808 с.

15. Самохіна ЕА, Седих НВ. Особенности организации занятий по черлидингу на этапе подготовки к соревнованиям детей 8-11 лет. Физическая культура и спорт. Харьков, 2017: 302-315

16. Чеппел.Р. Успешное тренерство по черлидингу. Нью-Йорк : Хьюмон Кинетикс, 1999. 364 с.

17. Human Kinetics. Coaching Youth Cheerleading (Coaching Youth Sports Series). Pom Headridge. 2009. 152 p.

\section{References}

1. Aftaikyn VS. Prymenenye uslozhnënnыkh uprazhnenyi dlia razvytyia koordynatsyonnukh sposobnostei yunыkh cherlydyrov na nachalnom эtape obuchenyia. Uchenыe zapysy unyversyteta ymeny P.F. Leshafta, 2015; 5: 24. 
2. Beketova AN. "Cherlydynh": Metodycheskye ukazanyia. Kharkov, 2017. 19 s.

3. Boliak AA. Chyrlidynh : Pravyla zmahan. Kharkiv, 2005, $82 \mathrm{~s}$.

4. Volkov LV. Teoryia y metodyka detskoho y yunosheskoho sporta: Uchebnyk. Kyiv: Olympyiskaia lyteratura, 2002. $245 \mathrm{~s}$.

5. Haverdovskyi YuK. Teoryia y metodyka sportyvnoi hymnastyky : Uchebnyk v 2-kh t. - M. : Sovetskyi sport, 2014.

6. Dolbysheva NH, Kydon V. Zakonomirnosti vzaiemozviazku tekhnichnoi, fizychnoi pidhotovlenosti ta funktsionalnoho stanu sportsmenok, yaki zaimaiutsia estetychnoiu himnastykoiu. Fizychna kultura, sport ta zdorovia natsii: zbir. nauk. prats. Zhytomyr : Vydavets O.O. Yevenok, 2017; 4 (23): 30-36.

7. Dolbysheva NH, Mykhailichenko AH. Tekhnichna ta fizychna pidhotovlenist cherlidyriv-flaeriv na etapi poperednoi bazovoi pidhotovky. Sportyvnyi visnyk Prydniprovia. Dnipro, 2018; 2: 22-26.

8. Lutsenko LS, Bodrenkova YA. Vzaymosviaz pokazatelei obshchei y spetsyalnoi fyzycheskoi podhotovlennosty sportsmenov-cherlyderov na эtape spetsyalyzyrovannoi bazovoi podhotovky. Fyzycheskoe vospytanye studentov. 2013; 6: 43-49. doi:10.6084/m9.figshare.840502

9. Matveev LP. Obshchaia teoryia sporta y ee prykladnыe aspektы : ucheb. posobye dlia vuzov fyzycheskoi kulturb. 5-e yzd., yspr. y dop. Moskva : Sovetskyi sport, 2010. $340 \mathrm{~s}$.

10. Zynchenko YA, Lutsenko LS, Boliak AA. Upravlenye trenyrovochnыm protsessom na osnove modelyrovanyia pokazatelei fyzycheskoi podhotovlennosty sportsmenov-cherlyderov spetsyalyzyrovannoho эtapa podhotovky. Slobozhanskyi naukovo-sportyvnyi visnyk. Kharkiv, 2010; 2: 52.

11. Mykhailienko AH. Tekhnichna pidhotovka v navchalno-trenuvalnomu protsesi yunykh sportsmeniv-cherlidyriv na etapi poperednoi bazovoi pidhotovky. Sportyvnyi visnyk Prydniprovia. Dnipro. 2018; 1: 55-58.

12. Mykhailichenko AH. Metodyka vdoskonalennia tekhnichnoi pidhotovky cherlidyriv na etapi poperednoi bazovoi pidhotovky. Naukovyi chasopys natsionalnoho pedahohichnoho universytetu im. M.P. Drahomanova. Naukovo-pedahohichni problemy fizychnoi kultury. Fizychna kultura i sport: zb. nauk. prats / Za red. H.A. Aorziutova. Kyiv: Vyd-vo NPU im. M.P. Drahomanova, 2018.

13. Noskova SA. Cherlydynh kak ynnovatsyonnыi vyd sporta v prepodavanyy fyzycheskoi kulturb v vыsshei shkole. Teoryia y praktyka fyzycheskoi kultury. Kharkov, 2002; 6: 49-51.

14. Platonov VN. Systema podhotovky sportsmenov v olympyiskom sporte. Obshchaia teoryia y ee praktycheskye prylozhenyia. Kyev : Olympyiskaia lyteratura, 2015. $808 \mathrm{~s}$.

15. Samokhina EA, Sedykh NV. Osobennosty orhanyzatsyy zaniatyi po cherlydynhu na эtape podhotovky k sorevnovanyiam detei 8-11 let. Fyzycheskaia kultura y sport. Kharkov, 2017: 302-315

16. Cheppel.R. Uspeshnoe trenerstvo po cherlydynhu. Niu-York : Khiumon Kynetyks, 1999. 364 s.

17. Human Kinetics. Coaching Youth Cheerleading (Coaching Youth Sports Series). Pom Headridge. 2009. 152 p.

\section{Цитування на цю статтю:}

Долбишева НГ, Михайліченко АГ. Взаємозв'язок показників технічної підготовленості спортсменівчерлідирів на етапі попередньої базової підготовки. Вісник Прикарпатського університету. Серія: Фізична культура. 2019 Берез 26; 33: 153-160

\begin{tabular}{|c|c|}
\hline Відомості про автора: & Information about the author: \\
\hline $\begin{array}{l}\text { Долбишева Ніна Григорівна - кандидат наук } 3 \\
\text { фізичного виховання і спорту, доцент, Придніпров- } \\
\text { ська державна академія фізичної культури і спорту } \\
\text { (Дніпро, Україна) }\end{array}$ & $\begin{array}{l}\text { Dolbysheva Nina Hryhorivna - Candidate of Science } \\
\text { (Physical Education and Sport), Associate Professor } \\
\text { (Ph. D.), Prydniprovska State Academy of Physical } \\
\text { Culture and Sports (Dnipro, Ukraina) }\end{array}$ \\
\hline \multicolumn{2}{|l|}{$\begin{array}{l}\text { e-mail: dolbysheva-nina@ rambler.ru } \\
\text { https://orcid.org/0000-0002-7306-9194 }\end{array}$} \\
\hline $\begin{array}{l}\text { Михайліченко Анна Геннадї̈вна - аспірантка, } \\
\text { Придніпровська державна академія фізичної куль- } \\
\text { тури і спорту (Дніпро, Україна) }\end{array}$ & $\begin{array}{l}\text { Mykhailichenko Anna Hennadiivna - post-graduate } \\
\text { student, Prydniprovska State Academy of Physical } \\
\text { Culture and Sports (Dnipro, Ukraina) }\end{array}$ \\
\hline e-mail: anya_mihailichen@mail.ru & \\
\hline
\end{tabular}

